\title{
Junior doctors' hours: the way forward
}

\author{
Managers and purchasers hold the key
}

Two and a half years ago all the key players signed up to the principles in Funior Doctors: The New Deal. ${ }^{12}$ Its central aim was that "by the end of 1994 junior doctors working in the busiest jobs will have maximum average hours of duty 72 per week." Initial progress seemed rapid: in the year to September 1991 the number of junior doctors contracted to work for more than 83 hours a week had halved ${ }^{4}$; the government funded 350 new consultant and 150 new staff grade posts.

Accurately determining the extent of progress has long been hampered by the reliability of data on contracted hours and definitions of rotas. ${ }^{5}$ Interviews between August and October 1992 found that $70 \%$ of 307 junior doctors in one region had contracts that underestimated how long they spent at work. The figures for contracted hours also underestimated the number of doctors working over 83 hours by one third. ${ }^{6}$

Earlier this year the minister of health, Dr Brian Mawhinney, asked Dr Graham Winyard, medical director of the NHS Management Executive, to review the achievability of medical staffing policies after concerns were expressed that the new deal's targets for 1994 could not be achieved without the appointment of more junior doctors or doctors in non-consultant career posts than Achieving a Balance permits. ${ }^{7}$ Such concerns dogged previous initiatives to reduce junior doctors' hours, and a review with a similar remit was completed in $1990 . .^{8}$ Its recommendations for further progress within the extant staffing controls included redistributing junior posts between and within regions, consultants contributing substantially to out of hours cover, or the introduction of shift systems.

The current options for progressing the new deal are similar, with some important qualifications. Shifts have not proved a panacea. Their uptake has been slower than expected: by November this year only $5 \%-13 \%$ of posts in English regions used them. ${ }^{9}$ Shifts are difficult to implement, and supervision and training of juniors may suffer. ${ }^{10}$ Encouraging juniors to work shifts may result in more operating out of hours with less supervision, contrary to the recommendations of the Confidential Enquiry into Perioperative Deaths.

Developing robust shift systems requires substantial changes in how services are delivered-medical staff need to be organised into teams rather than single consultant firms. Given the managerial complexity of such changes, the slow uptake of shift systems is unsurprising; however, simply fitting more junior or middle grade staff into rotas or shifts without extra consultant input will further dilute supervision. It also runs counter to the recommendations of the Calman report for shorter and more highly structured specialist training. ${ }^{11}$ Both the new deal and the Calman report critically depend on more consultant time being available. ${ }^{12}$ More visiting overseas doctors are unlikely to ease the problem as they will still require high levels of supervision and training.

A notable success of the new deal has been a closer examination of who does what. Todd identified the key questions 10 years ago: they are not how many doctors are needed for a safety net but what clinical tasks need to be performed out of hours and who should perform them. ${ }^{13}$ The importance of nursing staff in the implementation of the new deal was acknowledged at its inception and has grown steadily. ${ }^{14}$ Innovative solutions with nurses taking on new roles-for example, as nurse practitioners-can help. ${ }^{15} 16$
Relaxing the new deal's targets because of the difficulties in meeting them would be risky. Although progress has varied, some units have achieved the targets for 1994-suggesting that solutions are possible. The commitment of local managers seems important for success. Workable solutions have to evolve through a process of audit, and most units will have already embarked on the process with the targets for December 1994 in mind. Altering the targets in midplay will lead to confusion and a loss of credibility.

The government faces two major challenges in taking the new deal forward. The first is the quality of data on the numbers of junior doctors working in the NHS and the hours they work. Data on what they do when they are at work are even weaker, but they are the key to a rational approach.

The second challenge is to make the deal work in the context of the internal market. William Waldegrave retained junior doctors on national terms and conditions of service because they were a "national resource and not just the employees of any individual unit," 17 but neither that commitment nor the provision of central funding has spared the new deal from the effects of the market. The main concerns for any provider units are the views of its purchasers, and unless purchasers are convinced of the importance of funding more consultant time and more highly trained nurses any gains made may not be sustained.

The relation between the quality of hospital care and the hours worked by junior doctors was the driving force behind the new deal. ${ }^{18}$ The new deal sets out quality standards, which many purchasing authorities have not embraced with sufficient enthusiasm. The internal market has also set adjacent units in competition with each other and further complicated the rationalisation of acute services, long recognised as necessary to produce cost effective solutions to the problem of hours. ${ }^{8}$ It will be through addressing these issues rather than altering the targets or relaxing staffing controls that ministers can do most to forward the aims of the new deal and consolidate the progress already made.

PAUL McLAREN Senior registrar

St Martin's Hospital,

Canterbury CT1 1TD

1 Department of Health. funior doctors' hours; the new deal. London: DoH, 1991.

2 Department of Health. Heads of agreement on junior doctors' hours. London: DoH, 1990.

3 Department of Health. William Waldegrave announces new deal on junior doctors' hours. London: DoH, 1991. (Press release H91/262.)

4 Loveland P. The new deal: an account of progress in reducing junior hospital doctors' hours in England. Health Trends 1992;24:3-4.

5 Scotland A. The Dowie report: is it out of date? Br $\mathcal{F}$ Hosp Med 1990;43:1990.

6 Kelly C. Time out. Health Services fournal 1993:103:24-6.

7 United Kingdom Health Departments, Joint Consultants Committee and Chairmen of Regional Health Authorities. Hospital medical staffing: achieving a balance. London: Department of Health and Social Security, 1987.

8 Bartholomew DJ, Balmer DW. A study of junior hospital medical manpower in the NHS. London: London School of Economics and Political Science, 1990.

9 Junior Doctors Committee. Summary of the new deal progress. London: BMA, 1993.

10 Bulstrode CM, Bell Y, Muir Gray AJ. Senior house officers: the lost tribe. $\operatorname{Br} \mathcal{F}$ Hosp Med 1993;50:572.

11 Department of Health. Hospital doctors training for the future. The repon of the working party on specialist medical training. London: DoH, 1993.

12 Bulstrode CM, Muir Gray AJ, Anderson M, Hawke CI. New deal for junior doctors' hours: how to achieve it. $B M \mathcal{F} 1992 ; 305: 1203-5$.

13 Todd G. The challenge of medical manpower planning. Health Services Manpower Review 1983;9:3-6.

14 Directorate of Nursing and Quality, South East Thames Regional Health Authority. A new deal for nurses too? London: Royal Society of Medicine, 1993.

15 Morely B. Role of the night nurse practitioner. British fournal of Nursing 1992;1:719-21.

16 United Kingdom Central Council for Nursing, Midwifery, and Health Visiting. The scope of professional practice. London: UKCCNMHV, 1992.

17 Department of Health. William Waldegrave reassures junior doctors on pay and conditions and announces $446 m$ for the development of medical audit. London: DoH, 1991. (Press release H91/35.)

8 Poulton EC, Hunt GM, Carpenter A, Edwards RS. The performance of junior hospital doctors following reduced sleep and long hours of work. Ergonomics 1978;21:279-95. 